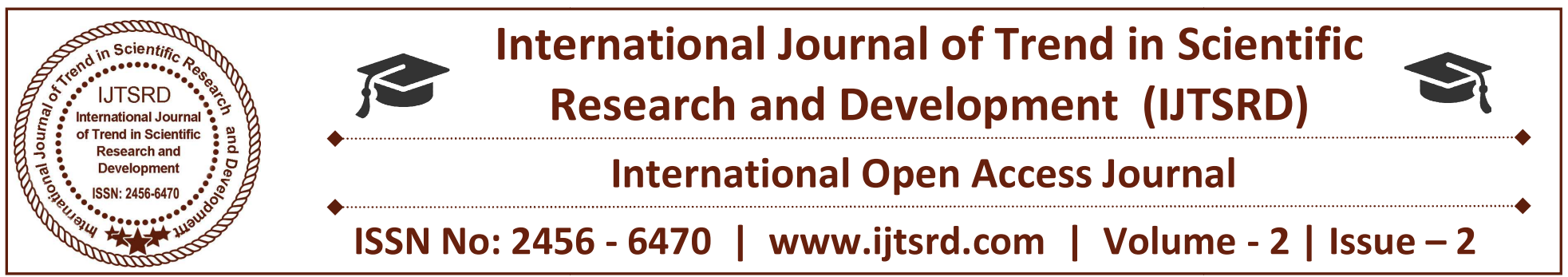

\title{
Consumer Awareness and Satisfaction towards Organic Products in Palakkad District-Kerala
}

\author{
Abisha. KA \\ Research Scholar, Sree Narayana Guru \\ College, K.G.Chavadi, Tamil Nadu, India
}

\author{
Dr. P. Kannan \\ Assistant Professor, Sree Narayana Guru \\ College, K.G.Chavadi, Tamil Nadu, India
}

\section{ABSTRACT}

The adoption of organic production and processing is highly determined by market demand. Therefore this is reflected in consumer's awareness and satisfaction towards organic food products. This research result indicated that the main reason for purchasing organic food products is an expectation of a healthier and environment friendly means of production. Organic buyer tend to be older and higher educated than who do not buy them. However, the main barrier to increase the market share of organic food product is consumer information.

Keywords: organic, agriculture, food products, pricing, certification standards

\section{INTRODUCTION OF THE STUDY}

Agriculture is currently changing into reworked into dynamic productive and profitable sector owing to ever-increasing demand for food and food products. So as to cope up with the food production target, a lot of stress is probably going to be to agricultural inputs. the employment of chemicals as plant protection practices acts as associate degree insurance against the danger of losing not solely the crop however additionally the cash spent on advanced technology used as inputs in achieving higher production. Breakthrough within the development of various agrochemicals and their widespread use at the farm level so has helped to spice up the agricultural production altogether countries.
During the standard technology amount in Asian country, the utilization of chemical was restricted primarily to the high price crops solely. The standard varieties failed to face a lot of downside of insect tormenter and diseases and if in any respect they occurred, the standard technique on the market may management them. However, the introduction of hybrids and adoption of intensive cropping practices, demanded high chemical use to see the yield losses. at the moment thousands of chemicals square measure used for agricultural production. Those chemicals act with completely different parts of the plant scheme and contamination might happen in respect of lelement or the opposite. In recent years use of chemicals particularly fertilizer and pesticides became a cause for serious concern because it has been marked out as pollutants having adverse effects on setting as well as person. In recent years many reports suggests that the agrochemical, particularly the chemical fertilizers square measure leading to setting degradation by manner of polluting plant and soil environment, water bodies, effecting the layer etc. They additionally contaminate the bottom water and surface water leading to eutrophication of water bodies.

Pesticides square measure currently extensively accustomed management varied pests, that square measure harmful to crops raised by man for food, feed and fiber production. although they need vie a crucial role in boosting the agricultural production, however, 
most of the chlorinated pesticides square measure non-biodegradable and leave residues, that square measure damaging to masses, animals and also the setting. Residue studies in Asian country have additionally discovered wide unfold contamination of the food merchandise and also the setting as a full. The presence of residues of insect powder in food commodities and alternative parts of the setting could be a matter of great concern. Even tiny quantities of the residues eaten daily at the side of food will build up to high level in body fat (Dhaliwal and Singh, 1993). There's so, a relentless worry that society is being slowly poisoned by the intake of food contamination with chemical residue.

whereas each the fertilizer and also the chemical usage has result in enlarged crop production and bigger economic come to the farmers, their impact on soil and water setting and crop quality wasn't thought of relevant till the last 10 years. There's currently increasing proof show that indiscriminate use of agrochemical will have adverse result on soil setting (Naidu et al, 1996).

Keeping the risky effects of inorganic fertilizers and also the agro-chemicals on setting similarly as on the person, therefore, it's associate degree pressing would like for the developing country like India to shift the organic agriculture from the present inorganic agriculture as most of the cultivable soils in India contain organic carbon below the brink level and majority of the farming community is resource poor and get of fertilizers and chemicals in adequate quantities is on the far side their capability. Agriculture is far and away the foremost vital occupation of the individuals of this region. The foremost of the farmers of this region square measure typically tiny and marginal in nature and square measure economically not sound and so, they can't afford to shop for the adequate quantity of fertilizers and chemicals necessary for the crop production.

Organic Agriculture can be a production system that avoids or for the foremost half excludes the use of chemical fertilizers, pesticides and growth regulators. The foremost aim of organic agriculture is to substantiate sustained productivity, environmental protection and making on the market food and food merchandise raised with none reasonably chemicals. Agriculture is primarily applied biology and is probably to attain success once it accepts and follows principles like (a) On farm waste exercise,

(b) Non-chemical weed management,

(c) Biological tormenter management,

(d) Integrated nutrient management for sustaining soil fertility and crop productivity.

With increasing health consciousness and concern for setting, organic farming system has been drawing attention all over the world. Organic farming will be a holistic production management system that promotes and enhances agro-ecosystems health additional as bio-diversity, biological cycles and soil biological activities. As a result, there is widespread organic movement and enormous demands for organic merchandise.

\section{OBJECTIVES OF THE STUDY}

1. To study consumer awareness about organic food products.

2. To study attitude of consumers buying and using of organic products.

3. To analysis the factors influencing to buy organic products among the consumers.

4. To identify the level of satisfaction of consumers towards organic products among the consumers.

5. To identify the problem faced by the organic consumer.

6. To study and suggest measures on how the consumption of organic food can be spread wider.

\section{SCOPE OF THE STUDY}

Organic food promotes a balance of human, other living organisms and the nature. It also promotes no artificial preservatives and best maintain the originality of food. This prevents excess use harmful ingredients and thereby ensures health. This study attempted to gain knowledge about consumer awareness towards organic food consumption and to see whether there is any potential this might have for changing their behavior. The rationale for carrying out this study is that consideration for the environment could come only from well-informed citizens who are aware of, and fully committed to their rights to a quality health and environment. Therefore consumer's awareness and satisfaction towards organic food will be the main aim of this study.

\section{RESEARCH METHODOLOGY}

The validity of any research is based on the systematic method of data collection and analysis. 
Both primary and secondary data were used for the present study. For collecting the primary data, 680sample respondents were selected from six taluks of Palakkad District by using stratified random sampling method.

\section{LIMITATIONS OF THE STUDY}

1. The study was conducted in Palakkad district of Kerala. Hence, the result may not be generalized to other areas of the country.

2. The sample consists of only Limited number of consumers.

3. The study is confined to main organic food products irrespective of numerous organic products available in the market.

4. The sampling and survey method adopted in this study has its own limitations. Thus, result of the study is subject to the above limitations

\section{REVIEW OF LITERATURE}

"A study on consumers' awareness towards organic food products with special reference to Tirupur district (Dr. D. T. Venkatakrishnan2017)" In today's world organic food product was important for the people at large to steer a healthy life. Became a basic necessity in human life. During this paper, a shot has been created to search out the shopper's awareness towards organic food. A sample of a hundred respondents ${ }^{\mathrm{ee}}$ was purposively elect from Tirupur District. The chosen samples area unit analyzed exploitation easy share, chi-square test and multivariate analysis test. It's found that 3variables particularly there exists any vital association between gender, age, qualification, monthly financial gain and client awareness towards organic food product of the respondent.

.Consumer Attitude and Purchase intension towards Organic Food (IrinSutha\& Solomon T, 2016)" the event of Organic food remains babe stage in India. it's necessary to understand regarding the patron perspective towards Organic food, supported shopper perspective model factors like shopper information, Environmental concern, personal norms, subjective norm and shopper purchase import square measure measured which permit America to seek out the patron perspective and get import on Organic food. customers disagree from one another; they have totally different concepts, taste, perception, likes and dislikes, perspective in easy term it's thought oriented
, if shopper has positive thought on organic food it will produce the acquisition import.

"Factors influence purchase of organic products in Nilgiri district (Mr. Sathis Kumar and Dr. E. Muthukumar, 2016)". It is known those customers in Nilgiri district gave additional importance to factors like health, environmental safety, information and culture wherever organic food was involved. However, they were indifferent towards attributes of organic food like style, color of the food etc.

\section{"The factors influencing organic food consumptions in China market}

(J. Thorgosen et al., 2015)". The paper according on the findings of the study into shopper perception toward beef and therefore the influence of those perceptions on consumption. The influence of attitudes and vital others (subjective norms) on intention to shopper were explored. The findings discovered that each perspective and therefore the subjective norm influenced intention to consume, however it absolutely was perspective that was found to be of bigger importance.

\section{ORGANIC FIC FARMING OR ORGANIC AGRICULTURE}

The term organic is rooted in bio from Greek bios meaning life or way of living. Organic food products was first coined in the 1940s and refers to food raised, grown and stored or processed without the use of synthetically produced chemicals or fertilizers, herbicides, pesticides, Fungicides, growth hormones and regulators or generic modification. (Essoussi \& Zahaf, 2008).Roddy, Cowan and Hutchinson (1994) view organic food products as a product of organic farming. Lampkin et al. (1999) thinks the term organic 'is best thought of as referring not to the type of inputs used, but to the concept of the farm as an organism, in which all the components - the soil, minerals, organic matter, Microorganisms, insects, plants, animals and humans -interact to create a coherent, self-regulating and stable whole. Reliance on external inputs, whether chemical or organic, is reduced as far as possible.

Organic Farming is a certifiable farm management system with controls and traceability that is in harmony with the local environment using land husbandry techniques such as soil-Conservation measures, crop rotation and the application of agronomic, biological and manual methods instead of 
synthetic inputs. This is different from Traditional few or no purchased inputs.

Farming, which is often subsistence oriented using

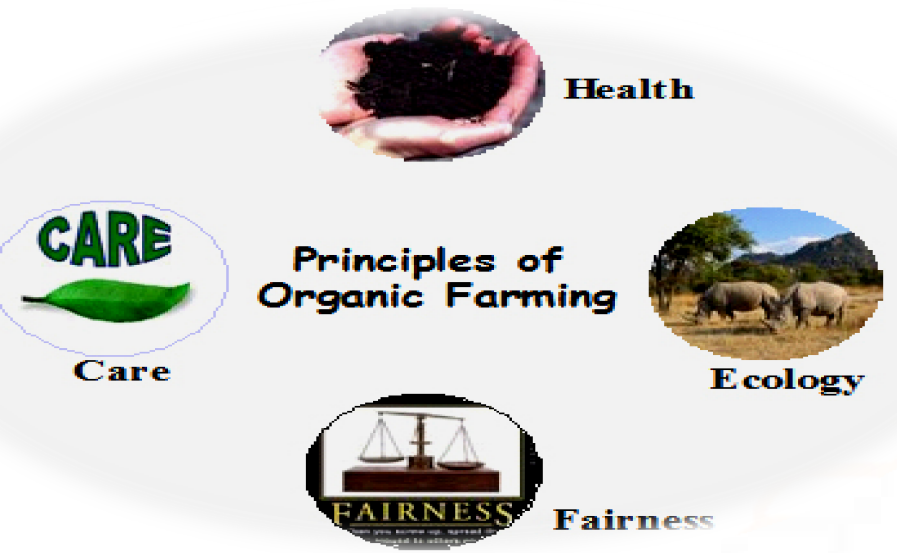

\section{ORGANIC FOOD}

Organic food is food produced by methods that comply with the standards of organic farming. Standards vary worldwide, but organic farming in general features practices that strive to cycle resources, promote ecological balance, and conserve biodiversity. Organizations regulating organic products may restrict the use of certain pesticides and fertilizers in farming. In general, organic foods are also usually not processed using irradiation, industrial solvents or synthetic food additives.

\section{ORGANIC CERTIFICATION}

It is a certification process for producers of organic food and other organic Agricultural products. In general, any business directly involved in food production can be certified, including seed suppliers, farmers, food processors, retailers and Restaurants. Requirements vary from country to country, and generally involve a set of production standards for growing, storage, processing, packaging and shipping that include:

- avoidance of synthetic chemical inputs (e.g. fertilizer, pesticides, antibiotics, food additives, etc) and genetically modified organisms;

o use of farmland that has been free from chemicals for a number of years (often, three or more);

$\circ$ keeping detailed written production and sales records (audit trail);

- maintaining strict physical separation of organic products from non-certified products;

$\circ$ undergoing periodic on-site inspections. In some countries, certification is overseen by the government, and commercial use of the term organic is legally restricted. Certified organic producers are also subject to the same agricultural, food safety and other government regulations that apply to non-certified producers.

\section{FINDINGS}

\section{AWARENESS ABOUT ORGANIC FOOD PRODUCTS}

- Among the Consumers, $51.5 \%$ of them are males, and the rest $48.5 \%$ are females. The overall mean agreeability score ranged from 1.80 to 1.81 and it is on par among gender group of Consumers.

- $46.0 \%$ of them belong to $25-40$ years of age group, followed by $29.4 \%$ belong to above 40 years of age group of Consumers. The overall mean agreeability score ranged from 1.70-1.84 and it is on par among age groups of Consumers.

- $51.8 \%$ of them belong to rural area, and the rest $48.2 \%$ of them belong to urban area. The overall mean agreeability score ranged from 1.78 to 1.83 and it is on par among location groups of Consumers.

- $61.8 \%$ of them are married, and the rest $38.2 \%$ are unmarried. The overall mean agreeability score ranged from 1.58 to 1.95 and it is higher among married group of Consumers.

- $36.2 \%$ of them are graduates, followed by $31 \%$ are professionals. The overall mean agreeability score ranged from 1.76 to 1.89 and it is on par among educational group of Consumers.

- $30.9 \%$ of them belong to other occupational group, followed by $19.1 \%$ are students group of Consumers. The overall mean agreeability score ranged from 1.64 to 1.93 and it is higher in agricultural group of Consumers.

- $55.6 \%$ of them belong to joint family, and the rest of them belong to nuclear family. The overall 
mean agreeability score ranged from 1.79 to 1.83 and it is on par among nature of family group of Consumers.

- $56.9 \%$ of them have up to 4 members in their family, and the rest $43.1 \%$ have above 4 members in their family. The overall mean agreeability score ranged from 1.78 to 1.82 and it is on par among the family size group of Consumers.

- $45.9 \%$ of them belong to below Rs.25, 000 monthly family income group, followed by 38.1 $\%$ belong to between Rs.25, 000-Rs.50, 000 monthly family income groups of Consumers. The overall mean agreeability score ranged from 1.65 to 1.91 and it is higher in Rs.25,000-Rs.50,000 monthly family income group of Consumers.

- $82.1 \%$ are familiar with organic agricultures, where as the rest $17.9 \%$ are not familiar about it. Thus the studies revealed that majority of the Consumers are familiar with organic agriculture.

- $51.2 \%$ buy organic vegetables, followed by 20.3 $\%$ buy other organic food products, $10 \%$ buy organic fruits, and the rest $13.5 \%$ buy dairy products. Thus the study revealed that majority of the Consumers buy organic vegetables.

- $48.5 \%$ are influenced by self interest, followed by $22.8 \%$ are influenced by friends and relatives, 9.4 $\%$ are influenced by books, news papers \& magazine, and $8.4 \%$ are influenced by colleague. Thus the study revealed that most of the Consumers are influenced by self interest.

- $38.8 \%$ purchase organic products weekly, followed by $28.1 \%$ purchase monthly, 14.7 purchase daily, and $5.6 \%$ purchase every six months Thus the study revealed that most of the Consumers purchase organic products weekly.

- $30.7 \%$ are using organic products between 1-2 years, followed by $29.9 \%$ are using between $3-5$ years, $26 \%$ are using for more than 5 years. Thus the study revealed that most of the Consumers are using the organic food products between 1-2 years.

- $39.4 \%$ willing to spend on organic products when it is priced same as conventional, followed by 24.7 $\%$ are willing when it is priced $1 / 4$ higher than conventional. Thus the study revealed that most of the Consumers are willing to spend on organic food when it is priced same as conventional.

- $31 \%$ pay attention seldom to information on food labels when purchasing organic products, followed by $21.6 \%$ pay attention often, $10.9 \%$ pay attention always. Thus the study revealed that most of the Consumers pay attention to food labels while purchasing organic food products.

- $87.9 \%$ expressed that there is need for a system of verification of organic food products, where as the rest $12.1 \%$ have expressed 'no' to it. Thus the study revealed that majority of the Consumers has expressed that there is need a system of verification of organic food products..

- $50.1 \%$ have said that the government is responsible for providing verification, followed by $17.6 \%$ have said an independent certification company is needed. Thus the study revealed that majority have said that the government is responsible for providing verification.

\section{ATTITUDE TOWARDS ORGANIC FOOD PRODUCTS}

- The overall mean agreeability score towards organic food products ranged from 3.09 to 3.27 and it is higher in male group of Consumers.

- The overall mean agreeability score on organic food products ranged from 3.27 to 3.55 and it is on par among age group of Consumers.

- The overall mean agreeability score on organic food products ranged from 4.05 to 4.15 and it is higher in rural group of Consumers.

- The overall mean Agreeability score on organic food products ranged from 3.09 to 3.36 and it is higher in married group of Consumers.

- The overall mean Agreeability score on Job satisfaction ranged from 3.87 to 4.15 and it is higher in graduate group of Consumers.

- The overall mean agreeability score on organic food products ranged from 3.89 to 4.24 and it is higher in business group of Consumers.

- The overall mean agreeability score on organic food products ranged from 4.08 to 4.13 and it is on par among nature of family group of Consumers.

- The overall mean agreeability score on organic food products ranged from 4.10 to 4.10 and it is on par among family size group of Consumers.

- The overall mean agreeability score on organic food products ranged from 4.07 to 4.16 and it is on par among family income group of Consumers.

- among the 5 points of purchase among the Consumer, the mean score ranged from 39.12 to 74.25 and the 'Organic store' secured higher mean score and stood at top, followed by 'Producer/Farmers' secured next higher mean 
score and stood at second, 'Generic supermarket' secured next higher mean score and stood at third .

- Among the 12 factors influencing to purchase of organic food products among the Consumer, the mean score ranged from 19.79 to 79.80 and the 'Health / Nutrition value' secured higher mean score and stood at top, followed by 'Taste' secured next higher mean score and stood at second, 'Price/Affordability' secured next higher mean score and stood at third

- Among the 5 factors increasing the level of trust towards organic food among the Consumer, the mean score ranged from 37.25 to 80.41 and the 'Government regulation' secured higher mean score and stood at top, followed by 'Scientific evidence on packaging' secured next higher mean score and stood at second, 'Celebrity endorsement' secured next higher mean score and stood at third

- Among 11 agreeability scores on organic food products, the mean score ranged from 3.07 to 3.84 and the statement Organic food have high nutritional value 'secured higher mean score and stood at top, followed by 'Consuming organic food tastes better than conventional products' secured next higher mean score and stood at second, the statement 'They are safe to consume / not contaminated' secured next higher mean score and stood at third.

- Among 5 reasons for preferring organic food products, the mean score ranged from 3.86 to 4.62 and the reason 'Necessity 'secured higher mean score and stood at top, followed by 'Health consciousness' secured next higher mean score and stood at second, 'Quality, authenticity and harmless' secured next higher mean score and stood at third.

\section{SATISFACTION TOWARDS ORGANIC FOOD PRODUCTS}

- Among the 10 reasons for preference towards organic food products, the mean satisfaction score ranged from 1.93 to 3.59 and the reason 'Taste 'secured higher mean score and stood at top, followed by 'Quality' secured next higher mean score and stood at second, 'Family Shelf Life' secured next higher mean score and stood at third.

\section{PROBLEMS FACED BY THE ORGANIC CONSUMERS}

- Among 7 problems faced by organic consumers, the mean score ranged from 3.86 to 4.44 and the reason 'Lack of Awareness about organic 'secured higher mean score and stood at top, followed by 'Organic products are not available' secured next higher mean score and stood at second, the reason 'Organic products are not easily available' secured next higher mean score and stood at third.

\section{PREFERENCE TOWARDS ORGANIC FOOD PRODUCTS}

- The overall mean preference score on Job satisfaction ranged from 4.33 to 4.42 and it is higher in female group of Consumers.

- The overall mean preference score on Job satisfaction ranged from 4.26 to 4.49 and it is higher in 25-40 years of age group of Consumers.

- The overall mean preference score on organic products ranged from 4.34 to 4.41 and it is on par among locations group of Consumers.

- The overall mean preference score on organic products ranged from 4.32 to 4.41 and it is higher married group of Consumers.

- The overall mean preference score among education group of the Consumers ranged from 4.16 to 4.69 and it is higher in illiterate group of Consumers.

- The overall mean preference score on organic products ranged from 4.17 to 4.48 and it is higher in other occupation group of Consumers.

- The overall mean preference score on organic products ranged from 4.27 to 4.51 and it is higher in joint family group of Consumers.

- The overall mean preference score on organic products ranged from 4.32 to 4.46 and it is higher in above 4 members in the family group of Consumers.

- The overall mean preference score on organic products ranged from 4.27 to 4.46 and it is higher in Rs.25,000-Rs.50,000 family income group of Consumers.

\section{ATTITUDE TOWARDS ORGANIC PRODUCTS}

- Factor analysis condensed and simplified the 11 Attitude statements and grouped into 4 Factors explaining $63.53 \%$ of the variability of all the 11 statements. 
- The Discriminate function analysis revealed that three variables namely OCCUP-X6, EDUCA-X5 and FSIZE-X8 are substantially important variable in discriminating between the two groups namely Consumers with lower overall mean agreeability score and Consumers with higher overall mean agreeability score towards Organic food products.

\section{SATISFACTION TOWARDS ORGANIC FOOD PRODUCTS}

- The overall mean satisfaction score on Job satisfaction ranged from 2.87 to 3.13 and it is higher in 51 and above years of age group of Consumers.

- The overall mean satisfaction score towards organic food products ranged from 2.86 to 3.16 and it is higher in above 40 years of age group of Consumers.

- The overall mean satisfaction score towards organic food products ranged from 2.87 to 3.12 and it is higher in 51 and above years of age group of Consumers.

- The overall mean satisfaction score towards organic food products ranged from 2.93 to 3.12 and it is higher in 51 and above years of age group of Consumers.

- The overall mean satisfaction score towards organic food products ranged from 2.92 to 3.08 and it is higher in graduate group of Consumers.

- The overall mean satisfaction score towards organic products ranged from 2.69 to 3.55 and it is higher in Govt services group of Consumers.

- The overall mean satisfaction score towards organic food product ranged from 2.77 to 3.19 and it is higher in nuclear family group of Consumers.

- The overall mean satisfaction score towards organic food products ranged from 2.89 to 3.08 and it is higher in up to 4 members in the family group of Consumers.

- The overall mean satisfaction score towards organic food product ranged from 2.98 to 3.04 and it is on par among family income group of Consumers.

- The inter-correlation matrix showed that the independent variables namely Awareness-X1, Attitude-X2, Preference-X3, and Problems-X4, are significantly correlated with the dependent variable Y-Satisfaction.

- The Path analysis showed that the three variables AWARE-X1, ATTITUDE-X2 and PROBLEM-
X4 are substantially important contributing variable for the dependent variable satisfaction -Y.

- The Multiple regression analysis showed that four variables Awareness-X1, Attitude-X2, Preference$\mathrm{X} 3$, and Problems-X4 towards organic food products have significantly contributing to Satisfaction-Y. and these variables put together explained the variations of satisfaction- $Y$ to the extent of $20.3 \%$.

\section{PROBLEMS FACED BY THE CONSUMERS}

- The overall mean agreeability score on problems faced by consumers ranged from 3.87 to 4.35 and it is higher in male group of Consumers.

- The overall mean agreeability score among organic consumers ranged from 4.03 to 4.20 and it is higher in above 40 years of age group of Consumers.

- The overall mean agreeability score on problems faced by organic Consumer ranged from 3.78 to 4.43 and it is higher in rural group of Consumers.

- The overall mean agreeability score on problems faced by organic Consumer ranged from 4.03 to 4.26 and it is higher in unmarried group of Consumers.

- A The overall mean Agreeability score on problems faced by organic Consumers ranged from 3.93 to 4.50 and it is higher in illiterate group of Consumers.

- The overall mean Agreeability score on Job satisfaction ranged from 3.64 to 4.48 and it is higher in Govt service occupation group of Consumers.

- The overall mean Agreeability score on problems faced among organic Consumer ranged from 3.90 to 4.29 and it is higher in nuclear family group of Consumers.

- The overall mean Agreeability score on problems faced by organic Consumers ranged from 4.10 to 4.13 and it is on par among family size group of Consumers.

- The overall mean Agreeability score on problems faced by organic Consumers ranged from 4.02 to 4.18 and it is higher in below Rs.25,000 family income group of Consumers.

- The Chi-square analysis showed that significant association between gender group and level of satisfaction on organic food products and it is concluded that the overall level of satisfaction depends on the gender group of the Consumers. 
- There is significant association between age group and level of satisfaction on organic food products and it is concluded that the overall level of satisfaction depends on the age group of the Consumers.

- There is significant association between locations group and level of opinion on satisfaction on organic food products and it is concluded that the overall level of satisfaction depends on the location group of the Consumers..

- There is significant association between age group and level of opinion on satisfaction on organic food products and it is concluded that the overall level of satisfaction depends on the marital group of the Consumers.

- There is significant association between education qualification group and level of satisfaction on organic food products and it is concluded that the overall level of satisfaction independent of the education qualification group of the Consumers.

- There is significant association between occupation group and level of satisfaction on organic food products and it is concluded that the overall level of satisfaction depends on the occupation group of the Consumers.

- There is significant association between nature of school group and level of satisfaction on organic food products and it is concluded that the overall level of satisfaction depends on nature of family group of the Consumers.

- There is significant association between family size group and level of satisfaction on organic food products and it is concluded that the overall level of satisfaction depends on the family size group of the Consumers.

- There is no significant association between annual income group and level of satisfaction on organic food products and it is concluded that the overall level of satisfaction is independent of the family income group of the Consumers

- The Fried man's non-parametric test showed that there is significant difference in overall mean rank on the attitude towards organic food products among the family income groups and it is higher above Rs.50, 000 income group and the mean rank is least in Rs.25,000-Rs.50,000 family income groups of Consumers.

\section{SUGGESTIONS}

1. Awareness and training program to farmer: Because more number of farmers is not growing without use of chemicals. Because farmer are go only production of high yield commercial crops so he will use more chemical fertilizer and pesticides. But some majority of farmer success in organic farming.

2. Government support: Government is all so support to grow of organic farming and all so farmer through good organic product market facilities, financial support and so on

3. Infrastructure facilities: Give to sport to postharvesting facilities for organic forming. Because possible to decline in yield during the conversion period, there is need to provide some form of incentives to affected farmer.

4. Package of product: Provide a good packing facilities to specific product

5. Development of marketing: There is all very important is to develop more marketing area. Because there is no regulated market facility in organic product.

6. Regulated market is all so give separate price facility and market facility in yard only. Because more number of consumer prefer organic product. But there no farmer, so it stimulate the farmer to grow the organic products

7. Give free certification facilities: The increase frequency of viewing the advertisement of organic food products and better taste would influence the purchase organic food products. The influence of advertisement of organic food products with an increase in education found particularly among consumer

\section{CONCLUSION}

Majority consumers were awake to organic food, its edges and issues related to conventional food. However, this awareness was comparatively a lot of among educated respondents. But still majority purchase conventional food and not organic frequently as a result of some outstanding reasons like -

1. High value of products

2. Lack of data connected from wherever to shop for.

3. Lack of straight forward likewise as regular accessibility

4. Risk of obtaining cheated

Therefore provide facet factors are capable for lack of Demand for organic food. Effective selling structure and necessary support from the governmental agencies for Organic food is needed. It also can be 
done through NGOs and alternative Government agencies since it's safer and healthier food beside personal sector participation. Improvement in provide chain management and production coming up with can solve the problems like irregular provide, restricted stocks. It's the time for government to require effective policy call in association with agriculture Department to encourage farmers to provide and market organic products.

\section{REFRENCES}

1. Chandrashekar HM. Consumers Perception towards Organic Products - A Study in Mysore City, International Journal of Research in Business Studies and Management. 2014; 1(1):6166.

2. Jasmin Pandiya, Nayankumar Vala. Profiling of Organic Food Buyers in Ahmedabad City: An Empirical StudyPacific Business Review International 2012; 5(1):19-25.

3. Barret et al(2006), Organic Certification and the UK Market :Organic imports from Developing countries, Food policy,27(4) Pp.301, August 2007
4. Suganya S, Aravinth S. Consumers Awareness and Attitude towards Organic Foods, Journal of International Academic Research for Multidisciplinary. 2014; 1(12):738-745.

5. Organic agriculture: Why is organic food more expensive than conven-tional food? Available from http://www.fao.org/organicag/oa-faq/oafaq5/en/. Accessed January 15,2014.

6. State of Science Review: Nutritional Superiority of Organic Foods. Availa-ble fromhttp://www.organiccenter.org/reportfiles/536 7_Nutrient_Content_SSR_FINAL_V2.pdf.

7. Farah Ayuni Shafle(2012) :Procedia -Social and behavioral Sciences.(2012) Vol no 49 pages 360367.

\section{Websites:}

1. http://www.shoporganic.com/index.htm

2. http://www.oranicfoodsandcafe.com/index.htm 